\title{
OS SENTIDOS ATRIBUÍDOS POR PROFESSORES À HISTÓRIA DA MATEMÁTICA NO ENSINO
}

\section{THE TEACHERS' SENSITIVES TO THE HISTORY OF MATHEMATICS IN TEACHING}

\author{
Francisco Wagner Soares Oliveira ${ }^{1}$ \\ Instituto Federal de Educação, Ciência e Tecnologia do Ceará \\ Ana Cláudia Gouveia de Sousa ${ }^{2}$ \\ Instituto Federal de Educação, Ciência e Tecnologia do Ceará
}

\begin{abstract}
Resumo
O presente estudo é um recorte de uma pesquisa desenvolvida como requisito para a obtenção do título de Licenciado em Matemática pelo Instituto Federal de Educação Ciência e Tecnologia do Ceará Campus Canindé, a qual teve como título: Concepções de professores de matemática sobre o uso da história no ensino (OLIVEIRA; SOUSA, 2017) e que se desenvolveu sob a perspectiva de uma pesquisa qualitativa documental com uma contribuição bibliográfica. Neste texto, ainda com a intenção de contribuir de alguma forma com o trabalho do professor em sala e a luz de uma pesquisa de campo, de uma abordagem qualitativa desenvolvemos nosso estudo tento como principal objetivo identificar a partir dos argumentos dos professores o sentido atribuído a história da Matemática no ensino. Para tanto, realizamos uma leitura acerca da literatura que versa a respeito da educação Matemática em especial a que trata da história da Matemática como tendência metodológica de ensino afim de identificar o sentido dado ao uso da história no ensino por parte de educadores matemáticos e a concepção dos professores da educação básica quanto a tal prática, e a partir de então trabalhamos com a aproximação e discussão dos referidos dados de forma a alcançarmos nosso objetivo. Mediante a concretização de nosso trabalho podemos observar dentre outros resultados que tanto os educadores da educação Matemática como também os professores da educação básica entendem como uma prática valiosa a inserção da história no ensino, isso porquê dentre outros pontos acreditam que sua incorporação pode tornar o processo de ensino e aprendizagem mais prazeroso, atrativo e significativo para os alunos.
\end{abstract}

Palavras-chave: História da Matemática; Ensino de Matemática; Valor da História no ensino.

\begin{abstract}
The present study is a cut of a research developed as a requisite for obtaining a bachelor's degree in Mathematics from the Federal Institute of Education Science and Technology of Ceará Campus Canindé, which had as its title: Conceptions of teachers of mathematics on the use of history in teaching (OLIVEIRA; SOUSA, 2017) and that developed from the perspective of a qualitative documentary research with a bibliographic contribution. In this text, with the intention of contributing in some way to

\footnotetext{
${ }^{1}$ franciscowagner2007@gmail.com

2 anaclaudia@ifce.edu.br
} 
the work of the teacher in the classroom and the light of a field research, from a qualitative approach, we developed our study as the main objective to identify, from the teachers' arguments, the sense attributed to history of mathematics in teaching. To do so, we make a reading about the literature that deals with Mathematics education, especially that which deals with the history of Mathematics as a methodological tendency of teaching in order to identify the meaning given to the use of history in teaching by mathematical educators and the conception of the basic education teachers about this practice, and from then on we worked with the approximation and discussion of said data in order to reach our goal. Through the accomplishment of our work we can observe among other results that both educators of Mathematics education as well as teachers of basic education understand as a valuable practice the insertion of history in teaching, this because among other points believe that its incorporation can make the process of learning and learning more enjoyable, attractive and meaningful for students.

Keywords: History of Mathematics; Mathematics Teaching; Value of History in teaching.

\section{Introdução}

O ensino de Matemática tem ganhado cada vez mais relênvacia tanto dentro das instituições de ensino como também em pesquisas nacionais. Esse fato se deu com maior vigor a partir das orientações presentes nos Parâmetros Curriculares Nacionais PCN (BRASIL, 1998) e nas Orientações Curriculares Nacionais para o Ensino Médio OCNEM (BRASIL, 2006).

Os quais têm, dentre outras firnalidades, apresentar aos professores da educação básica possíveis formas de se trabalhar didaticamente o conteúdo matemático do currículo de modo a possibilitar aos alunos uma aprendizagem mais efetiva e significativa.

De tais formas de trabalho com os conhecimentos do currículo de matemática, nosso estudo se desenvolveu tendo como foco a incorporação da história da matemática no ensino, a partir do observado na pesquisa monográfica de graduação, intitulada "Concepções de professores de matemática sobre o uso da história no ensino" (OLIVEIRA; SOUSA, 2017) e em nossas leituras iniciais nos PCN (BRASIL, 1998), nas OCNEM (BRASIL, 2006) e em referenciais como Mendes (2009), dentre outros trabalhos acadêmicos sobre o tema.

Nesse sentido consideramos que o uso da história da matemática no ensino pode contribuir tanto para o aluno a atribuir ainda mais sentido à aprendizagem e à aplicação de determinados conteúdos como também ao trabalho do professor, o qual pode 
possivelmente, dentre outros fatores, encontrar um suporte para a sua prática docente, seja esse suporte didático, pedagógico ou até mesmo teórico.

Nessa perspectiva, e a partir das fontes de estudo mencionadas anteriormente, desenvolvemos este trabalho com o objetivo de identificar os sentidos atribuídos por professores à história da matemática no ensino.

\title{
Quadro teórico metodológico
}

De forma a identificar os sentidos atribuídos à história no ensino de Matemática por parte dos professores, realizamos uma pesquisa de campo, de abordagem qualitativa. Vale destacar que a pesquisa em que constam as concepções dos professores quanto ao uso da história no ensino foi realizada com 08 (oito) professores de escolas públicas, sendo que 04 (quatro) destes atuam em institições de ensino fundamental II, 03 (três) de ensino médio e outro nestes dois níveis de ensino.

Sob tal perspectiva de pesquisa, cabe observar que em nosso estudo consideramos o processo de construção dos entendimentos e sentidos atribuídos pelos professores, a partir das concepções apresentadas por eles referentes ao tema em estudo. A esse respeito Ponte (1992, p. 01) afirma que:

\begin{abstract}
As concepções têm uma natureza essencialmente cognitiva. Actuam como uma espécie de filtro. Por um lado, são indispensáveis pois estruturam o sentido que damos às coisas. Por outro lado, actuam como elemento bloqueador em relação a novas realidades ou a certos problemas, limitando as nossas possibilidades de actuação e compreensão.
\end{abstract}

Sustentados em tal afirmação é que elegemos como fonte principal para identificar os sentidos atribuídos à história da matemática no ensino por parte dos professores, o estudo em que constam as concepções dos professores quanto ao uso da história no ensino, as quais foram coletadas a partir da utilização de um questionário como instrumento de pesquisa.

Quanto aos sentidos atribuídos à história da matemática no ensino por parte dos educadores e pesquisadores estudados, podemos observar o entendimento de Siqueira (2007, p. 25) ao afirmar que:

A História da Matemática, é uma tendência da Educação Matemática bastante interessante. Ela permite compreender a origem das idéias que deram forma à cultura e observar também os aspectos humanos do seu 
desenvolvimento, como por exemplo, os homens que criaram essas idéias e estudar as circunstâncias em que elas se desenvolveram.

Ainda nesse sentido, Chaquiam (2015) defende que a insersão da história pode possibilitar os alunos a compreenderem o processo de elaboração do conhecimento matemático, de forma que a partir de então entendam a matemática como uma criação humana. Também nesse tocante BALESTRI et al. (2008, p. 04) destacam que:

- A história da matemática satisfaz a curiosidade do aluno e o motiva;

- A história da matemática ajuda veicular a Matemática como uma criação humana, uma manifestação cultural;

- A história da matemática ajuda a mudar concepções a respeito da natureza da matemática;

- A história da matemática ajuda a compreender como o conhecimento escolar está organizado;

- A história da matemática fornece respostas a alguns "por quês";

- A história da matemática oferece contexto para a compreensão de tendências da Educação Matemática;

- A história da matemática oferece um campo comum aos interesses de especialistas de várias áreas do conhecimento, favorecendo a realização de trabalhos multidisciplinares;

- A história da matemática auxilia na compreensão da noção de rigor matemático e da dimensão estética da Matemática;

- A história da matemática contribui para valorização da dimensão éticopolítica da matemática.

Também nesse sentido, Mendes (2009) defende que a incorporação da história da matemática por meio da valorização de seu processo histórico no desenvolvimento das atividades de ensino pode contribuir para facilitar o entendimento das faces cotidiana, escolar e científica da Matemática por parte dos alunos.

Entretanto, apesar desses sentidos positivos dados ao uso da história no ensino por parte de alguns pesquisadores, nos chamou a atenção notar as objeções apresentadas por Vianna (1998, p. 03), as quais indicam que:

1) O passado da matemática não é significativo para a compreensão da matemática atual;

2) Não há literatura disponível para uso dos professores de Primeiro e Segundo Graus;

3) Os poucos textos existentes destacam os resultados mas nada revelam sobre a forma como se chegou a esses resultados;

4) O caminho histórico é mais árduo para os estudantes que o caminho lógico;

5) O tempo dispendido no estudo da História da Matemática deveria ser utilizado para aprender mais matemática.

Esse contraponto é importante quando se busca construir conhecimentos sobre um tema e para uma melhor compreensão dos diferentes aspectos envolvidos nas 
diferentes concepções sobre o uso didático da história da matemática especificamente. Aspectos estes que vão desde a formação dos professores até o currículo escolar, passando pelas socondições objetivas de trabalho e de inserção das diferentes tendências metodológicas do ensino da matemática, não como conteúdos a mais, mas articulados aos objetos matemáticos ensinados.

\section{Discussão dos resultados}

Pelo observado nas considerações dos autores mencionados em nosso referencial, podemos obsevar que diferentemente das objeções levantadas por Vianna (1998), quanto à incorporação da história no ensino, a maioria dos educadores a entende como uma prática valiosa ao processo de ensino e aprendizagem da matemática. No estudo que versou sobre "Concepções de professores de matemática sobre o uso da história no ensino" (OLIVEIRA; SOUSA, 2017) essas objeções também não se fazem presentes na concepção dos professores quanto a tal incorporação da história no ensino.

De posse de tais fontes mencionadas anteriormente passamos a identificar, a partir dos argumentos dos professores, alguns dos sentidos atribuídos à história da matemática no ensino. Para tanto, cabe observa a seguir o quadro 01, que contém as concepções dos 08 (oito) professores que foram sujeitos da pesquisa de campo mencionada anteriormente, quanto ao uso da história no ensino, sendo cada professor representado respectivamente por $\mathrm{A}, \mathrm{B}, \mathrm{C}, \mathrm{D}, \mathrm{E}, \mathrm{F}, \mathrm{G}$ e $\mathrm{H}$.

Quadro 01 - A concepção dos professores quanto ao uso da história no ensino.

Indagação: Qual a sua concepção sobre o uso Didático da História da Matemática em aulas da Educação Básica?

É essencial, pois precisamos compreender melhor os resultados, unindo a teoria à prática. (A)

Essencial, pois facilita contextualização da disciplina. (B)

Importante pois a base de todo sistema de ensino da matemática necessita desse conhecimento, pois é necessário para uma aprendizagem de qualidade. (C) Percebi que quando os alunos conhecem a origem e aplicabilidade de determinados assuntos sentem-se mais "atraídos" em aprender. (D)

Em alguns conteúdos é importantíssimo a abordagem do conteúdo por meio do contexto histórico. (E)

Informar de onde surgiu a matemática daquele conteúdo trabalhado e a importância do mesmo para sua vida. (F)

Uma forma de despertar o interesse do aluno para aprender matemática. $(\mathrm{G})$

Considero importante para que os estudantes compreendam o contexto dos conceitos 
e entendam os "por quê's"; a definição a demonstração de conceitos e fórmulas. $(\mathrm{H})$ Fonte: Elaborado pelos autores

Pelas respostas apresentadas pelos professores no quadro acima podemos observar que suas concepções quanto ao uso da história no ensino, mesmo que, por meio de perspectivas diferentes, todos são favoráveis à realização dessa prática em sala como forma de possibilitar aos alunos uma aprendizagem mais atraente e significativa.

Assim, pelas concepções observadas, podemos inferir que elas indicam os sentidos atribuídos pelos professores, que entendem a incorporação da história no ensino de matemática como uma prática valiosa para a construção de conhecimentos no estudo dessa disciplina.

Em outras palavras as concepções revelam que os professores compreendem que a história da matemática merece se fazer presente no ensino de matemática, devido a suas possíveis potencialidades didáticas que podem emergir quando incorporada no processo de ensino e aprendizagem.

Cabe observar também que as objeções coletadas por Vianna (1998) quanto ao uso da história no ensino, assim como se divergem do entendimento dos pesquisadores levantados em nosso referencial teórico, também divergem dos sentidos atribuídos a essa prática por parte dos professores da educação básica investigados neste estudo.

\section{Considerações finais}

Pelo que podemos observar em reforço a nossa hipótese levantada inicialmete, a história da matemática é compreendida por grande parte dos professores como uma possibilidade didática capaz de possibiliatar ao trabalho do professor caminhos e/ou meios que possam vir a auxiliar no processo de ensino e aprendizagem da Matemática de forma a torná-la para os alunos um saber ainda mais contextualizado com a evolução e desenvolvimento da humanidade.

Observação essa que indica um importante e positivo sentido atribuído por parte dos professores a tal incorporação da história. Dessa forma, percebemos que, assim como alguns pesquisadores da matemática consultados, os professores da educação básica, sujeitos desta pesquisa, também julgam o uso da história no ensino como uma prática valiosa. 
Acreditamos que a identificação desse valor positivo dado ao uso da história no ensino por parte da maioria dos professores possa possivelmente influenciar a concepção de outros que porventura ainda não a entendem como uma prática valiosa ao ensino de matemática. Isso pode encontrar explicação no que afirma Ponte (1992), segundo o qual nossas concepções são por vezes influenciadas pelas representações sociais dominantes.

Contudo, esperamos que com esse estudo possamos contribuir com as escolhas metodológicas dos professores ao terem que trabalhar com determinados conteúdos da matemática sob a intenção de desenvolver em seus alunos uma aprendizagem mais significativa e contextualizada com o meio em que vivem.

\section{Referências}

BALESTRI, Rodrigo Dias; CYRINO, Márcia Cristina de Costa Trindade; SAVIOLI, Ângela Marta Pereira das Dores. A participação da história da matemática na formação de professores de matemática na óptica de professores/pesquisadores. In: ENCONTRO BRASILEIRO DE ESTUDANTES DE PÓS-GRADUAÇÃO EM EDUCAÇÃO MATEMÁTICA - EBRAPEM, 12, 2008, Rio Claro. Educação matemática: possibilidades de interlocução: anais eletrônico ... Rio Claro: UNESP, 2008. Disponível em: < http://www2.rc.unesp.br/eventos/matematica/ebrapem2008/upload/345-1-AGT4_balestri_tc.pdf >. Acessado em: 13 Jan. 2017.

BRASIL. Ministério da Educação. Secretaria de Educação Fundamental. Parâmetros curriculares para o ensino fundamental. Matemática. Brasília, MEC/SEF, 1998.

BRASIL. Secretaria de Educação Básica. Orientações Curriculares para o Ensino Médio / Ciências da natureza, matemática e suas tecnologias / Secretaria de Educação Básica. - Brasília: Ministério da Educação, 2006. 135 p.

CHAQUIAM, Miguel. História da Matemática em sala de aula: proposta para integração aos conteúdos matemáticos. In: XI Seminário Nacional de História da Matemática, 2015, Natal/RN. XI SNHM. Natal/RN: SBHMat, 2015.

MENDES, Iran Abreu. Investigação histórica no ensino da matemática. Rio de Janeiro: Editora Ciência Moderna Ltda, (2009).

OLIVEIRA, Francisco Wagner Soares; SOUSA, Ana Cláudia Gouveia de. Concepções de professores de matemática sobre o uso da história no ensino. $2017.70 \mathrm{f}$. TCC (Graduação) - Curso de Licenciatura em Matemática, Instituto Federal de Educação Ciência e Tecnologia do Ceará - IFCE, Canindé, 2017.

PONTE, João Pedro da. Concepções dos professores de matemática e processo de formação. ResearchGate. Lisboa/PT., 1992. Disponível em:< 
https://www.researchgate.net/publication/277037993_Concepcoes_dos_Professores_de _Matematica_e_Processos_de_Formacao.> Acesso em: 01 outubro de 2016.

SIQUEIRA, Regiane Aparecida Nunes de. Tendências da educação matemática na formação de professores / Regiane Aparecida Nunes de Siqueira. 2007. 49 f. Monografia (Especialização em Educação Científica e Tecnológica) - Universidade Tecnológica Federal do Paraná, Campus Ponta Grossa. Departamento de Pesquisa e Pós-Graduação. Ponta Grossa, 2007.

VIANNA, Carlos. Roberto. Usos didáticos para a história da matemática. In: I Seminário Nacional de História da Matemática - SNHM, 1998, Recife. In.: ANAIS. Editor: Fernando Raul Neto. Recife: Universidade Federal Rural de Pernambuco, 1998. p. 65-79. 